\title{
UJI EFEKTIVITAS BEBERAPA PESTISIDA NABATI TERHADAP MORTALITAS (Spodoptera exigua Hubner) PADA TANAMAN BAWANG DAUN (Allium fistulosum L.)
}

\author{
Oleh : \\ Yuliani*) $^{*}$ \\ Widya Sari*) \\ Nia Fatimah**) \\ Email : yuliani.sains@unsur.ac.id
}

\begin{abstract}
Abstrak
Bawang daun merupakan salah satu komoditas tanaman hortikultura yang banyak dikonsumsi masyarakat namun produktivitasnya terganggu oleh serangan hama seperti, Spodoptera exigua. Dalam pengendaliannya petani masih menggunakan pestisida kimia sintetis yang memiliki banyak dampak negatif, seperti resistensi hama, resurgensi dan timbulnya hama sekunder. Pengendalian S. exigua menggunakan pestisida nabati dengan konsentrasi yang tepat dapat mengendalikan hama ulat bawang daun secara efektif dan tidak berdampak negatif terhadap tanaman dan lingkungan. Penelitian ini bertujuan untuk mengetahui efektivitas dari beberapa pestisida nabati (daun babadotan, nimba dan sirsak)dengan menggunakan beberapa konsentrasi terhadap mortalitas S. exigua. Penelitian ini menggunakan Rancangan Acak Lengkap (RAL) Faktorial terdiri dari dua faktor dengan masing-masing 3 ulangan,. Faktor pertama yaitu jenis pestisida nabati : babadotan, nimba dan sirsak, Faktor kedua adalah konsentrasi pestisida nabati yaitu : $250 \mathrm{~g} / \mathrm{L}, 500 \mathrm{~g} / \mathrm{L}$ dan tanpa pestisida nabati (kontrol). Hasil pengamatan menunjukkan bahwa jenis pestisida tidak berpengaruh nyata terhadap mortalitas $S$. exigua. Sedangkan konsentrasi pestisida nabati berpengaruh nyata terhadap mortalitas. Mortalitas terbaik yaitu pada perlakuan babadotan $500 \mathrm{~g} / \mathrm{L}$ dan Nimba $500 \mathrm{~g} / \mathrm{L}$, mencapai $100 \%$ kematian pada 6 hsa. Hasil analisis $\mathrm{LT}_{50}$ yang terbaik pada perlakuan babadotan $500 \mathrm{~g} / \mathrm{L}$ dan nimba $500 \mathrm{~g} / \mathrm{L}$ yaitu : 2,93 hari dan 2,57 hari.
\end{abstract}

Kata kunci : daun babadotan, daun nimba, daun sirsak, pestisida nabati, Spodoptera exigua

\section{Abstract}

Leaf onion is a horticultural plant commodity that is widely consumed by many people, but its productivity is dismpted by pests such as Spodoptera exigua. In controlling these pests, farmers still use synthetic chemical pesticides which have many negative impacts, such as pest resistance, resurgence and the emergence of secondary pests. Control of $S$. exigua using biopesticides with the right concentration can control these pests effectively and do not have a negative impact on plants and the environment. This study aims to determine the effectiveness of several biopesticides (babadotan, neem and soursop leaves) by using several concentrations on the mortality of $S$. exigua. This study used a completely randomized design (CRD) factorial consisting of two factors with 3 replications. The first factor is the type of plant as a biopesticide: babadotan, Neem and Soursop, the second factor is the concentration of biopesticides, namely :250 g/L, $500 \mathrm{~g} / \mathrm{L}$ and no biopesticides (control. The results showed that the type of biopesticide had no significant effect on the mortality of $S$. exigua. Meanwhile, the concentration of biopesticides significantly affected the mortality of $S$. exigua. The best mortality was on babadotan $500 \mathrm{~g} / \mathrm{L}$ and $500 \mathrm{~g} / \mathrm{L}$ neem treatment, reaching 100\% mortality on day 6.The best LT50 analysis results were on babadotan $500 \mathrm{~g} / \mathrm{L}$ and $500 \mathrm{~g} / \mathrm{L}$ neem treatments, respectively: 2, 93 days and 2.57 days.

Keywords: babadotan leaves, neem leaves,biopesticides, Spodoptera exigua.

*)Dosen Fakultas Sains Terapan UNSUR

**) Alumni Fakultas Sains Terapan UNSUR

UJI EFEKTIVITAS BEBERAPA PESTISIDA

YULIANI, WIDYA SARI dan NIA FATIMAH

NABATI TERHADAP MORTALITAS

(Spodoptera exigua Hubner) PADA TANAMAN

BAWANG DAUN (Allium fistulosum L.) 


\section{PENDAHULUAN}

Bawang daun (Allium fistulosum L.) merupakan salah satu komoditas hortikultura yang berasal dari kawasan Asia Tenggara sangat berpotensi dikembangkan secara intensif dan komersil. Tanaman jenis sayuran daun sebagai bahan bumbu dapur dan pencampur sayur mayur sebab mamebagikan aroma yang harum serta rasa yang enak dan juga sebagai bumbu masakan dan kaya khasiat, banyak digunakan di Indonesia.

Permintaan pasar terhadap tanaman bawang daun akan semakin meningkat seiring dengan meningkatnya laju perkembangan penduduk. Kenaikan permintaan berasal dari industri mie instant yang menggunakan bawang daun sebagai bumbu bahan penyedap rasa (Sutrisna et al., 2003).

Pertumbuhan produksi rata-rata bawang daun menurut provinsi di jawa barat adalah total kurang lebih 1 juta kwintal (BPS Provinsi Jawa Barat, 2016). Sebab itu setiap aspek yang mempengaruhi tingkat produksinya sangat penting untuk diperhatikan.

Hama yang sering dijumpai pada tanaman bawang daun ialah ulat grayak (Spodoptera exiqua) merupakan salah satu jenis hama pemakan daun yang sangat penting. Kehilangan hasil akibat serangan hama tersebut dapat mencapai $80 \%$, bahkan puso jika tidak dikendalikan (Marwoto dan Suhartono, 2008). Ulat ini hampir terdapat di semua tanaman baik dari tanaman pangan seperti bawang daun, kedelai dan jagung, juga pada tanaman hortikultura seperti cabe, kubis, kacang panjang dan lainnya. Biasanya menyerang tanaman dengan cepat, serentak dan dalam areal yang cukup luas. Ulat ini hanya tampak dan menyerang pada malam hari, sedang di siang hari ulat grayak relatif tidak aktif dan bersembunyi di sela-sela pelepah daun dan baru mulai aktif pada sore hari Marni et al., (2018). Menurut Zuraya, (2013) kehilangan hasil dan kerugian akibat serangan hama ulat bawang bisa mencapai $57 \%$ karena terjadi sejak fase pertumbuhan sampai dengan fase pematangan umbi. Gejala yang ditimbulkan oleh serangan hama ulat daun yaitu akan terlihat transparan atau timbul bercak putih.

Pengunaan pestisida nabati yang merupakan pestisida yang bahan dasarnya berasal dari bagian organ tanaman seperti batang, daun bunga, buah, biji, dan akar. Pestisida nabati relatif tidak meracuni manusia, hewan dan tanaman lainnya karena sifatnya yang mudah terurai sehingga tidak menimbulkan residu (Untung, 1994).

Pengendalian S. exigua menggunakan pestisida nabati dengan konsentrasi yang tepat dapat mengendalikan hama ulat bawang daun secara efektif dan tidak berdampak negatif terhadap tanaman. Oleh sebab itu perlu diketahui jenis tanaman untuk pestisida nabati dan konsentrasi yang tepat dalam mengendalikan hama ulat pada bawang daun ini.

Tujuan dari penelitian ini adalah untuk mengetahui efektivitas beberapa pestisida nabati dengan beberapa konsentrasi terhadap mortalitas hama ulat pada bawang daun S. exigua.

\section{METODE PENELITIAN}

\section{Waktu dan Tempat}

Penelitian ini dilaksanakan bulan Februari-Mei 2020. Penelitian ini dilaksanakan di Balai Penelitian Tanaman Pangan dan Hortikultura Wilayah I Bojongpicung, Cianjur, Jawa barat. Dan di Kebun Percobaan, Ciranjang, Cianjur

\section{Alat dan Bahan}

Alat yang digunakan untuk penelitian ini adalah blender, saringan, gelas ukur $1000 \mathrm{ml}$, timbangan, handsprayer, kertas saring, wadah plastik atau kayu, gelas plastik, polybag, gunting, kertas label, alat dokumentasi, alat tulis.

Bahan yang digunakan yaitu larva S. exigua instar 3, daun babadotan, nimba, dan sirsak, aquades, kain kasa, kapas, jaring net, plastik mika, tanah sebagai 
media tanam, stek tanaman bawang daun siap tanam.

\section{Perbanyakan Larva S.exigua}

Larva dibiakkan dengan pakan alami dan madu diletakkan pada wadah kayu atau plastik, dipelihara di laboratorium yaitu memelihara mulai dari menetaskan telur, memberi pakan larva hingga tumbuh menjadi imago (dewasa) hingga dapat menghasilkan generasi 1 yang nantinya instar tiga yang akan dipergunakan sebagai serangga uji.

\section{Pembuatan Ektrak Pestisida Nabati}

Daun babadotan, daun nimba, daun sirsak yang masih segar disiapkan masing-masing $1 \mathrm{~kg}$. Lalu daun babadotan, daun nimba, daun sirsak dijemur pada panas matahri hingga kering. Selanjutnya, daun-daun yang sudah kering tersebut dihancurkan dengan cara menggunakan alat blender hingga halus menjadi tepung. Larutan ditambahkan air per liter masing-masing konsentrasi 250 $\mathrm{g} / \mathrm{L}$, dan $500 \mathrm{~g} / \mathrm{L}$.

\section{Persiapan Tanaman Uji Dan Invenstasi Hama \\ Stek tanaman bawang daun} disiapkan untuk ditanam dan dipelihara sebagai tanaman uji tiap perlakuan. Investasi hama larva instar-3 S.exigua sebanyak 10 ekor per tanaman dilakukan setelah tanaman bawang daun berumur 4 minggu, kemudian tanaman tersebut diberi sungkup.

\section{Aplikasi Ekstrak Pestisida Nabati}

Ekstrak daun babadotan, daun nimba, daun sirsak masing-masing pada tanaman bawang daun dengan volume semprot 2,4 $\mathrm{ml} /$ tanaman dan frekuensi penyemprotan 2 hari sekali selama 3 kali.

\section{Rancangan Penelitian}

$$
\text { Penelitian menggunakan }
$$

Rancangan Acak Lengkap (RAL) faktorial, Pengujian aplikasi beberapa konsentrasi dan jenis ekstrak pestisida nabati terhadap mortalitas $S$. exigua pada tanaman bawang daun. Faktor Jenis pestisida nabati yang digunakan yaitu daun babadotan (A), daun nimba (B), dan daun sirsak (C). Perlakuan jenis konsentrasi yaitu (1) $0 \mathrm{~g} / \mathrm{L}$, (2) $250 \mathrm{~g} / \mathrm{L}$, (3) $500 \mathrm{~g} / \mathrm{L}$. Setiap kombinasi perlakuan dilakukan pengulangan masing-masing 3 kali.

\section{Parameter Pengamatan}

Pengumpulan data dilakukan selama 7 hari pada perlakuan pengaplikasian beberapa jenis dan konsentrasi esktrak pestisida nabati. Dalam penelitian ini parameter pengamatan terdiri dari :

\section{Mortalitas}

Menunjukkan tingkat kemampuan atau daya bunuh beberapa ekstrak pestisida nabati babadotan, sirsak dan nimba dalam membunuh hama ulat bawang diperoleh dengan rumus (Fagooge et al.,1981 dalam Setiawan, 2014).

Keterangan:

$$
M=\frac{b}{a+b} \times 100 \%
$$

$\mathrm{M}=$ Presentase mortalitas hama;

$\mathrm{a}=$ Jumlah $S$ exigua yang mati.

$\mathrm{b}=$ Jumlah $S$ exigua yang hidup.

\section{Menentukan Nilai $\mathbf{L T}_{50}$}

Penentuan Nilai $\mathrm{LT}_{50}$ dilakukan dengan analisis probit menggunakan software Minitab 2018. Nilai LT 50 panjang waktu saat $50 \%$ larva uji rasio sudah mati dan $50 \%$ larva uji lainnya masih hidup. Waktu rasio ekor/jam, jumlah total larva adalah 420 ekor larva yang dibagi menjadi 10 larva disetiap konsentrasi pada 3 kali pengulangan.

\section{Teknik Analisis Data}

Data hasil penelitian yang diperoleh, dianalisis dengan menggunakan software Minitab dan Microsoft excel. Analisi pengaruh signifikan antara parameter uji dengan metode sidik ragam ANOVA (Analisis of Variance) Two way, apabila ada beda nyata maka diuji lanjut antar variable pengamatan dengan menggunakan uji Tukey pada taraf 5\%. 


\section{HASIL DAN PEMBAHASAN}

Hasil pengujian statistik rerata mortalitas S. exigua pada beberapa jenis dan konsentrasi pestisida nabati pada pengamatan $1-6$ hsa. Data rata rata mortalitas larva S. exigua diolah secara statistik menggunakan uji ANOVA, selanjutnya dilakukan uji lanjutan menggunakan uji Tukey pada taraf 5\%. (Tabel 1).

Berdasarkan data dari Tabel 1 menunjukkan bahwa pada jenis pestisida nabati yang diujikan pada larva $S$. exigua berbeda nyata pada pengamatan hari ke 1 setelah pengaplikasian pada jenis B (Nimba) sebesar 11\%. lebih cepat dibandingkan A (Babadotan) dan C (Sirsak), Pada hari berikutnya jenis pestisida tidak berbeda nyata, namun nilai dari jenis pestisida masing masing memiliki kereaktifan yang signifikan. Karena kandungan senyawa yang terdapat dalam tanaman efektif mengendalikan larva. Sesuai dengan Thamrin et al., (2007) menyatakan selain memiliki senyawa aktif utama dalam ekstrak tumbuhan juga terdapat senyawa lain yang keberadaannya dapat meningkatkan aktivitas ekstrak secara kesuluruhan (sinergi). Dari keseluruhan pestisida nabati yang diujikan tidak berpengaruh nyata terhadap kematian larva $S$. exigua.

Hari pertama pada konsentrasi $500 \mathrm{~g} / \mathrm{L}$ memiliki pengaruh yang sangat tinggi sebesar $15,6 \%$ dibandingkan konsentrasi $250 \mathrm{~g} / \mathrm{L}$ sebesar $89 \%$ dan konsentrasi 0 sebagai kontrol sebesar $0 \%$. pada hari ketiga konsentrasi $250 \mathrm{~g} / \mathrm{L}$ sudah mulai menunjukkan hasil yang sama dengan konsentrasi $500 \mathrm{~g} / \mathrm{L}$. pada hari terakhir, konsentrasi $250 \mathrm{~g} / \mathrm{L}$ dan $500 \mathrm{~g} / \mathrm{L}$ memiliki besar pengaruh yang nyata. Hal ini berkaitan dengan konsentrasi yang diaplikasikan, semakin tinggi konsentrasi yang diaplikasikan maka akan semakin tinggi kematian larva $S$. exigua. Purba (2007) dalam penelitiannya mengatakan bawa peningkatan konsentrasi berbanding lurus dengan peningkatan bahan racun tersebut, sehingga daya bunuh semakin tinggi.

Tabel 1. Rerata Tingkat Mortalitas (\%) Larva S. exigua Terhadap Perbedaan Jenis dan Konsentrasi Pestisida Nabati.

\begin{tabular}{|c|c|c|c|c|c|c|}
\hline \multirow{2}{*}{ Perlakuan } & \multicolumn{6}{|c|}{ Pengamatan hari ke- } \\
\hline & 1 & 2 & 3 & 4 & 5 & 6 \\
\hline Jenis Pestisida Nabati & $*$ & tn & tn & tn & tn & tn \\
\hline A (Babadotan) & $0,44 \mathrm{~b}$ & $1,78^{a}$ & $2,78^{a}$ & $4,56^{a}$ & $5,56^{a}$ & 6,33 a \\
\hline B (Nimba) & $1,11 \mathrm{a}$ & 2,22 a & $3,22^{a}$ & $4,22^{a}$ & $5,44^{\text {a }}$ & $6,44^{\text {a }}$ \\
\hline C (Sirsak) & $0,89 \mathrm{a}$ & $1,56^{\mathrm{a}}$ & $2,56^{a}$ & $3,78^{a}$ & $5,00^{\text {a }}$ & 6,44 a \\
\hline Konsentrasi & $*$ & $*$ & $*$ & $*$ & $*$ & $*$ \\
\hline Tanpa & $0,00 \mathrm{c}$ & $0,00 \mathrm{c}$ & $0.00^{b}$ & $0.00^{b}$ & $0.00^{\mathrm{c}}$ & $0.00^{b}$ \\
\hline $250 \mathrm{~g} / \mathrm{L}$ & $0,89 \mathrm{~b}$ & $2,33 \mathrm{~b}$ & $3,78^{a}$ & $5,44^{\text {a }}$ & $7,11 \mathrm{~b}$ & 9,33 a \\
\hline $500 \mathrm{~g} / \mathrm{L}$ & $1,56 \mathrm{a}$ & $3,22 \mathrm{a}$ & $4,78^{a}$ & 7,11 a & 8,89 a & $9,88^{\text {a }}$ \\
\hline
\end{tabular}

Keterangan : Angka yang diikuti notasi huruf pada kolom yang sama dan diikuti huruf yang sama tidak berbeda nyata menurut uji tukey taraf $\alpha=95 \%$. (*) Berbeda nyata (tn) Tidak berbeda nyata.

Hasil menunjukkan bahwa pengaruh perlakuan interaksi beberapa jenis dan kosentrasi pestisida nabati pada jumlah dan waktu kematian S.exigua, semuanya berpengaruh walaupun tidak memberikan perbedaan yang nyata. Dibuktikan dengan kenaikan garis pada grafik menunjukkan yang mati lebih tinggi pada perlakuan D (Nimba $500 \mathrm{~g} / \mathrm{L})$ yang menyebabkan lebih banyak populasi larva 
menurun dengan cepat ditandai dengan kenaikan garis pada grafik. Kaitannya dengan aktivitas makan, serangga dapat mengenali senyawa-senyawa asing dalam makanannya walaupun dalam konsentrasi rendah dan akan merespon atas kehadiran senyawa tersebut dalam makanannya. Yunia (2006) yang menyatakan kehadiran senyawa-senyawa yang belum dikenal (foreign compounds) dapat mengakibatkan penolakan pada serangga.

Hasil data mortalitas harian selanjutnya diolah lanjut probit analysis menggunakan program software Minitab 18 untuk mendapatkan nilai LT50. hasil analisis LT50 didapat berbagai nilai estimate atau nilai rata-rata kematian pada masing-masing perlakuan, antara jenis pestisida ekstrak babadotan, nimba dan sirsak dengan $250 \mathrm{~g} / \mathrm{L}$ dan $500 \mathrm{~g} / \mathrm{L}$ ditunjukkan dalam tabel 2 .

Hasil pengamatan menunjukkan semakin tinggi konsentrasi dari ketiga jenis pestisida nabati nilai LT50- nya semakin kecil. Pada perlakuan dengan pemberian nimba(500g/L)didapatkan bahwa mortalitas $50 \%$ larva S. exigua dengan nilai LT 50 terkecil yaitu :2,57; yang diikuti pada perlakuan pestisida nabati babadotan $(500 \mathrm{~g} / \mathrm{L})$ dengan nilai LT 50 : 2,93 (Tabel 2.)

Tabel 2. Nilai $\mathrm{LT}_{50}$ dari Kombinasi Pestisida Nabati terhadap S. exigua.

\begin{tabular}{lc}
\hline \multicolumn{1}{c}{ Perlakuan } & Nilai LT50 (hari) \\
\hline Babadotan (2500g/L) & 3,58 \\
Babadotan (500g/L) & 2,93 \\
Nimba (250g/L) & 3,48 \\
Nimba (500g/L) & 2,57 \\
Sirsak (250g/L) & 3,65 \\
Sirsak (500g/L) & 3,62 \\
\hline Ket: LT 50 Lethal Time 50 (waktu yang dibutuhkan untuk mematikan 50\% populasi larva uji).
\end{tabular}

Kematian yang dialami oleh seluruh larva akibat adanya metabolit sekunder utama pada tanaman nimba yang berfungsi sebagai Azadirachtin yang terbentuk secara alami memiliki efek berupa antifeedant dengan menghasilkan stimulan penolak makan yang mengganggu persepsi rangsangan untuk makan (Mordue Luntz et al., 1998).

Aplikasi ekstrak babadotan selain mengakibatkan kematian kurang lebih dalam 3 hari setelah aplikasi pada larva, babadotan juga aktif dalam penghambatan atau penolakan makan. Prijono (1999) yang menyatakan bahwa Anti juvenile hormone yang terkandung di dalam babadotan menganggu tahapan proses perkembangan larva.

Daun sirsak mengandung bahan aktif yang terdapat pada senyawa acetogenin dimana di dalamnya terdapat annonain, saponin, flavanoid, tanin yang dapat berfungsi sebagai antifeedant (Kardinan 2002).

\section{KESIMPULAN}

Berdasarkan hasil penelitian yang telah dilakukan, maka dapat disimpulkan:

1. Jenis pestisida nabati tidak berpengaruh nyata terhadap mortalitas larva S. exigua.

2. Konsentrasi pestisida nabati berpengaruh nyata terhadap mortalitas larva S.exigua yaitu Babadotan $500 \mathrm{~g} / \mathrm{L}$ dan Nimba $500 \mathrm{~g} / \mathrm{L}$.

3. Interaksi perlakuan jenis dan konsentrasi pestisida nabati tidak berpengaruh nyata terhadap mortalitas S. exigua.

4. LT 50 terkecil terdapat pada perlakuan pemberian pestisida nabati nimba (500 $\mathrm{g} / \mathrm{L})$ yaitu : 2,57 hari dimana terjadi kematian 50\% pada larva uji S.exigua. 


\section{DAFTAR PUSTAKA}

BPS Provinsi Jawa Barat. 2016. Badan Pusat Statistik Provinsi Jawa Barat. https://jabar.bps.go.id/. Akses 11-07-2019.

Kardinan. 2002. Pestisida Nabati Ramuan dan Aplikasi. Penerbit Penebar Swadaya. Jakarta.

Marni, Meidiwarman, \& Thei, R. S. P. 2018. Pengaruh Beberapa Bioinsektisida Terhadap Populasi Hama (Spodoptera exigua H) dan Produksi Tanaman Bawang Merah (Allium ascalonicum L.). Agroekoteknologi. (01):1-15

Marwoto, \& Suharsono. 2008. Strategi dan Komponen Teknologi Pengendalian Ulat Grayak (Spodoptera litura Fabricius) pada Tanaman Kedelai. Penelitian Tanaman Kacang Kacangan. 91(5) :1689-1699.

Mordue (Luntz) AJ et al.,1998. Actions of azadirachtin, a plant allelochemical, against insects. Pesticide Science. 54(3): 277-284

Prijono, D. 1999. Prospek dan Strategi Pemanfaatan Insektisida Alami Dalam PHT. Bahan Pelatihan Pengembangan dan Pemanfaatan Insektisida Alami. Pusat Kajian PHT. Institut Pertanian Bogor. Bogor. Hal 1-7.

Purba, S. 2007. Uji Efektivitas Ekstrak Daun Mengkudu (Morinda citrifolia) Terhadap Plutella xylostella
L. (Lepidoptera : Plutellidae) di Laboratorium. Skripsi. Universitas Sumatera Utara. Medan. Hlm 2935.

Setiawan, A. N. dan Achmad S. 2014. Uji Efektivitas Berbagai Konsentrasi Pestisida Nabati Bintaro (Cerbera manghas) terhadap Hama Ulat Grayak (Spodoptera litura) pada Tanaman Kedelai. Planta Tropika Journal of Agro Science. 2(2).

Sutrisna, N., Ishak, I., \& Suwalan, S. 2003. Kajian rakitan teknologi budidaya bawang daun. Jurnal. Kajian Teknologi Pertanian. 6(1) :64-72.

Thamrin, M., Asikin, S., Mukhlis, \& Budiman, A. 2005. Potensi ekstraktan flora lahan'rawa sebagai pestisida nabati. Balai Penelitian lahan dan rawa. Hal 31-49.

Untung, K. 1994. Konsep Pengendalian Hama Terpadu (PHT). Andi Offset. Yogyakarta

Yunia, N. 2006. Aktivitas Insektisida Campuran Ekstrak Empat Jenis Tumbuhan Terhadap Larva Crocidolomia pavonana (F.) (Lepidoptera:Pyralidae). Institut Pertanian Bogor. Hlm 1-53.

Zuraya, N. 2013. Produksi Bawang Merah di Cirebon Turun. Republika Online.

https:// nasional.republika.co.id/be rita/mpli5q/produksi-bawangmerah-di-cirebon-turun. Akses pada 07-11-2019. 